\title{
JUSTICIA Y LIBERTAD EN LEIBNIZ
}

\section{JUSTICE AND FREEDOM IN LEIBNIZ}

\author{
Randal Carrera \\ Universidad de Costa Rica \\ carrera1526@gmail.com
}

Recibido: 22 de setiembre / Aceptado: 2 de octubre / Publicado: 9 de noviembre

\begin{abstract}
Resumen
En esta investigación se defiende la tesis de que en Leibniz, tanto la justicia como la libertad poseen un claro asidero metafísico, expresado en el papel que cumple la Divinidad como referente para el actuar humano. Se aborda, en un primer momento, la relación entre justicia divina y justicia humana planteada por Leibniz. Posteriormente, se profundiza en el tema de la libertad, particularmente en lo relacionado al libre albedrío y a la libertad de indiferencia. Finalmente se esbozan algunas conclusiones en torno al aporte de estas categorías al pensamiento político actual.
\end{abstract}

\section{Palabras claves}

Leibniz, teorías de justicia, libertad, libre albedrío, libertad de indiferencia.

\begin{abstract}
This research defends the thesis that in Leibniz's philosophy, both justice and freedom have an evident metaphysical grip, conveyed in the role of Divinity as a reference for human action. At first, the relationship between divine and human justice raised by Leibniz is addressed. Subsequently, the subject of freedom is deepened, particularly in the relation to free will and freedom of indifference. Finally, some conclusions are outlined regarding the contribution of these categories to current political thought.
\end{abstract}

\section{Keywords}

Leibniz, justice theories, freedom, free will, freedom of indifference. 


\section{Ubicación}

El pensamiento de Gottfried Wilhelm Leibniz (1646-1716) es conocido ampliamente en el ámbito de las ciencias exactas, particularmente por su aporte a la física y a las matemáticas, tal como se manifiesta en sus investigaciones en torno al cálculo infinitesimal y la noción de fuerza. Sin embargo, en los últimos años se ha evidenciado en el ambiente académico una clara preocupación por rescatar y sistematizar sus aportes en materia ética y política.

En este autor se encuentra un abordaje formal y sistemático de los temas que más preocupaban a la sociedad del siglo XVII. Su pensamiento político se caracteriza por su vínculo con la realidad, alejado de todo ideal utópico y de la construcción de un imaginario de nuevas formas de gobier$\mathrm{no}^{1}$. Leibniz es una figura que interviene directamente en la política de su tiempo, a partir de su rol como consejero real, por medio del diseño de una propuesta que vincula directamente lo político con lo ético. Factor que está siempre presente en la política, no tanto por referirse a la moralidad que debe orientar al grupo gobernante, sino por el hecho de que son los valores morales y el deseo de poder los elementos que mueven y motivan a los que detentan el poder ${ }^{2}$. La obra política de Leibniz se encuentra orientada por un claro matiz ético, el cual ofrece los fundamentos que deben dirigir el quehacer político. Esto implica una referencia directa con el ámbito metafísico, particularmente en lo relacionado con el tema de la existencia de Dios como principio clarificador de la existencia humana.

A tenor de estos presupuestos, esta investigación se aboca a abordar la reflexión política de Leibniz desde las nociones de justicia y libertad, en el horizonte de su justificación metafísica y en íntima relación con la ética. Se considera que estas temáticas reúnen los elementos claves de su pensamiento en esta materia y ofrecen las luces necesarias para conocer la postura del autor sobre temáticas íntimamente vinculadas con la sociedad y el hombre. Por estas razones, se encuentran fuera del objeto de estudio otras nociones relacionadas con su pensamiento político, tales como la tolerancia, el poder o la legitimidad del Estado.

\footnotetext{
1 Cf. Álvaro Carvajal, "Ética y política en Leibniz", Revista de Filosofia de la Universidad de Costa Rica, XXXVII .92 (1999), 70.

2 Cf. Jaime de Salas, "Prólogo”, en Escritos politicos, (Madrid: Centro de Estudios y Publicaciones, 1979), 15.
} 


\section{Justicia divina y justicia humana}

Leibniz señala que la justicia puede considerarse como la virtud más necesaria, ya que permite establecer el orden político y determina la subsistencia de los seres humanos en la sociedad, por lo que representa una de las características fundamentales que debe poseer todo gobernante. "La justicia es la virtud que los príncipes más necesitan. Las otras [se refiere a las virtudes que perfeccionan al ser humano] no hacen sino reforzar su gloria, mientras que ésta tiene en el Estado una función semejante a la de la razón en la naturaleza" 3 .

A través de una metodología deductiva, aborda una serie de conceptos y fundamentos de naturaleza metafísica, partiendo de la realidad divina hasta llegar a la experiencia humana ${ }^{4}$. En este sentido, lo que está en juego para Leibniz es el esclarecimiento de un principio que le permita comprender el mundo y su actividad; por lo que la reflexión sobre la naturaleza divina juega un papel secundario. Para este pensador, no es posible utilizar las reglas irrefutables del pensamiento para establecer un significado preciso de la noción de justicia; desde su perspectiva, es más importante "precisar la razón formal de la justicia y el criterio con el que hemos de determinar si nuestras acciones son justas o no"5. Esta razón formal que sustenta la justicia humana encuentra su asidero en la justicia divina.

Es importante mencionar que su reflexión sobre la justicia se encuentra pletórica de recursos pedagógicos, tales como las reiteraciones y las analogías, las cuales son diseñadas de forma clara y sumamente sencilla. Abandona, por momentos, la presentación sistemática de su pensamiento para abrir espacio a una especie de diálogo con "un otro", el cual, al estilo de las filosofías de la alteridad, sirve de base para desarrollar sus presupuestos fundamentales sobre el significado verdadero de la justicia.

Sin embargo, esta fundamentación de la justicia no es tan fácil de asimilar. Es tan difícil como la comprensión de las funciones que el cerebro realiza sobre los sentidos y el conocimiento, acota Leibniz. De igual manera, la monarquía divina es convulsa a los ojos de la persona, tal como sucede con

3 Gottfried Wilhelm Leibniz, "Retrato de un príncipe", en Escritos políticos (Madrid: Centro de Estudios y Publicaciones, 1979), 143.

4 Cf. Gottfried Wilhelm Leibniz, "Meditación sobre la noción común de justicia”, en Escritos políticos (Madrid: Centro de Estudios y Publicaciones, 1979).

5 Leibniz, "Meditación sobre la noción común de justicia”, 282. 
una novela cuyo desenlace no puede comprenderse al inicio de su lectura. Por ende, la belleza y justicia del mundo divino ha de encontrarse oculta a los ojos humanos.

Para Leibniz la verdadera justicia es más que el simple hecho de limitarse a no dañar a nadie, aspecto que conlleva una dimensión caritativa.

Vas a ser favorecido con un gran bien, pero surgen obstáculos. Puedo eliminarlos sin dificultad. ¿No crees tener en cierta manera, el derecho de pedirme que lo haga y de recordarme que yo te lo pediría a ti en una situación semejante? ${ }^{6}$.

Con esta aplicación, Leibniz desea evidenciar que la justicia se comprende plenamente al ubicarse en la posición del prójimo: "Ponte en el lugar del otro y estarás en la verdadera perspectiva de saber lo que es justo y lo que no lo es" ${ }^{7}$. Por lo tanto, es válido afirmar que, para este autor, la justicia implica una sintonía con los principios que rigen la justicia divina y una clara relación con los otros, es decir, con el prójimo. Desde su visión, la justicia humana debe coincidir con el parecer de Dios, principio y autor de todas las cosas.

Desde esta perspectiva, la justicia es una verdad eterna y necesaria, por lo que posee valor objetivo, es expresión y búsqueda de la armonía universal, cuya mayor ejemplificación se encuentra en Dios. De manera complementaria a estas tesis, Leibniz propone que la justicia posee un vínculo directo con el poder, ya que representa el uso de la prudencia en su ejercicio con los demás, aspecto que va de la mano con no causar daño a los otros ni a uno mismo $^{8}$. Esto conlleva que la aplicación de la justicia implique el ejercicio de la autoridad, de forma que "la justicia no la deben hacer las mismas personas usando simplemente la fuerza, tiene que haber una autoridad o alguien más importante que obligue a los ciudadanos a obedecer"9. De ahí el vínculo existente entre la justicia y el ejercicio del poder por parte del Estado.

Cabe mencionar que en Leibniz pueden distinguirse tres grados de justicia: la conmutativa, relacionada de manera directa con el evitar el daño a los demás; la distributiva, la cual implica dar a cada uno lo suyo con el objetivo de acrecentar la felicidad, y la universal, imbricada de manera directa

6 Leibniz, "Meditación sobre la noción común de justicia", 295.

7 Leibniz, "Meditación sobre la noción común de justicia", 298.

8 Cf. Gottfried Wilhelm Leibniz, Elementos del derecho natural, (Madrid: Tecnos, 1991).

9 Carvajal, "Ética y política en Leibniz”, 74. 
a una vida honesta en la cual se subordine la felicidad terrenal a la eterna ${ }^{10}$. La noción de justicia desarrollada en esta investigación se vincula, de manera expresa, con esta última categorización, por orientarse a la búsqueda de la felicidad común y que de manera particular expresa la armonía que debe existir entre el amor propio y el amor al prójimo.

\section{Aspectos claves de la libertad}

En palabras de Concha Roldán (1990), el aporte de Leibniz en lo relacionado al tema de la libertad radica en tratar de conciliar dos posturas antagónicas, tales como el determinismo y el libre albedrío, en un diálogo abierto con sus contemporáneos. Pues "nada causa más horror a Leibniz que la opinión de quienes sostienen que la voluntad humana para ser libre, puede y debe actuar sin motivos suficientes"11.

Para comprender este planteamiento, es necesario abordar sus tesis en torno al libre albedrío y a la libertad como determinación racional, tal como se detalla a continuación.

\subsection{El Libre albedrío}

Leibniz es partidario de una libertad exenta de coacción, lo que significa que las razones para actuar nunca pueden ser indiferentes en su acción. Ya que cuanto menos presiones externas y mayor conocimiento, más libre será la persona. De manera que la libertad es proporcional a los aprendizajes, partiendo del presupuesto de que Dios ha otorgado al ser humano la capacidad de distinguir entre el bien y el mal; razón por la que el libre albedrío no conlleva a la capacidad de obtener todo cuanto se desea, pues el ser humano no quiere por querer sino por la condición natural de querer lo que se considera mejor.

Esto implica una noción de libertad sustentada en la capacidad de actuar sobre lo que se haya juzgado más conveniente a través de un proceso racional, "solo ostentaremos un libre albedrío en cuanto nos sirvamos de la razón en aquellas cosas que no excedan nuestras fuerzas"12.

10 Cf. Elizabetta Di Castro, "El concepto de justicia en Leibniz", Revista de Filosofia de la Universidad de Costa Rica, LI (enero-diciembre 2012), 370.

11 Concha Roldán, "Prólogo", en Escritos en torno a la libertad, el azar y el destino, en Escritos en torno a la libertad, el azar y el destino, (Madrid: Tecnos, 1990), XIII.

12 Gottfried Wilhelm Leibniz, "Del libre albedrío", en Escritos en torno a la libertad, el azar y el destino, (Madrid: Tecnos, 1990), 112. 


\subsection{Libertad como determinación racional}

Leibniz menciona que el hecho de que el ser humano esté facultado para elegir lo mejor, no significa que siempre elija lo necesario: "el hombre es libre, pues, por más que elija siempre entre dos cosas aquella que le parezca lo mejor, no lo hace de forma necesaria" ${ }^{13}$. Por esta razón enfatiza que en el ser humano, a diferencia de Dios, sus acciones pueden ser contingentes o no necesarias. Para Leibniz se puede considerar necesario aquello cuyo contrario implique contradicción, por tanto, las cosas humanas no son necesarias, sino simplemente elegidas por Dios, esto es, algo puede ser cierto y orientar la elección, pero no estrictamente necesario.

El aspecto de que las razones que inclinan y orientan las acciones no sean en algunos casos necesarias, no modifica, en absoluto, la contingencia y la libertad. Desde su perspectiva, la libertad de indiferencia es imposible de encontrar aun en Dios, ya que Él se encuentra determinado en sí mismo para hacer lo mejor y las criaturas se encuentran determinadas por razones internas o externas. "Las sustancias son más perfectas cuanto más autodeterminadas y alejadas de la indiferencia están. Ya que al hallarse constantemente determinadas, tal determinación provendrá de sí mismas, siendo por tanto, más poderosas o perfectas, o la obtendrán del exterior, viéndose obligadas entonces a servir de mediación a otras cosas" ${ }^{14}$.

Leibniz enfatiza la incongruencia, imperfección e imposibilidad de encontrar una indiferencia absoluta en el actuar del sujeto; pues cuanta mayor imperfección, mayor determinación externa; por ende, cuando más se utilice la capacidad racional, habrá más libertad ${ }^{15}$. Por tanto, no es posible la denominada libertad de indiferencia, limitada a la libertad de querer, que es suspender la acción y la voluntad sin ninguna razón; pues todo posee una causa, sería rechazar lo mejor sin ninguna razón verdadera. Quedaría el ser humano a la suerte de la ignorancia, "puesto que cuanto más instruido se sea, menos indiferente o inseguro se estará acerca de la elección que uno debe

13 Gottfried Wilhelm Leibniz, "Acerca de la libertad carente de necesidad de elección”, en Escritos en torno a la libertad, el azar y el destino, (Madrid: Tecnos, 1990), 194.

14 Gottfried Wilhelm Leibniz, "Definición de libertad", en Escritos en torno a la libertad, el azar y el destino, (Madrid: Tecnos, 1990), 208.

15 Gottfried Wilhelm Leibniz, "Sobre la libertad de indiferencia", en Escritos en torno a la libertad, el azar y el destino, (Madrid: Tecnos, 1990), 117. 
hacer; y cuanto más habituado se esté a seguir la razón, más determinado se estará a ejecutar aquello que se juzga como lo más razonable"16.

\section{Conclusiones}

Este breve recorrido por algunos aspectos del pensamiento político de Leibniz permite elucidar las siguientes conclusiones:

El pensamiento político de Leibniz es abundante, no se limita a repetir los discursos vigentes en el contexto; por el contrario, desde una perspectiva realista ilumina el tema político con tesis propositivas. En su construcción se evidencian aspectos relacionados de manera directa con el factor ético. Su elaboración, aunque no rehúye la sistematización, se elabora, en muchos casos, con elementos de naturaleza pedagógica; por medio de ejemplos y analogías. Este es un aspecto que llama la atención en un autor cuya lectura no es sencilla, donde su pensamiento filosófico y científico es construido a través de categorías y conceptos sumamente complejos y de difícil comprensión.

En esta elaboración pedagógica de su pensamiento político, Leibniz ofrece un panorama ético de gran riqueza, en el cual se visualiza la preocupación por el otro, por aquel que se constituye en el prójimo. El uso de estas nociones puede denominarse como un verdadero antecedente de las filosofías contemporáneas dedicadas al tema de la alteridad.

El tema metafísico es fundamental para comprender el pensamiento político de este autor, es la base para la estructuración de su propuesta. Sin embargo, este referente es solamente un recurso teórico para justificar sus postulados políticos. A Leibniz no le interesa construir una sociedad justa y libre, fruto de una convicción religiosa; la apelación a un orden trascendente es solamente un referente necesario. Es decir, estas nociones metafísicas son utilizadas con una finalidad política concreta.

Las nociones de justicia y libertad no pueden comprenderse sin este hontanar metafísico. Este asidero es también, a la vez, un óbice para una relectura de la propuesta política de Leibniz, debido a que en la actualidad la filosofía política utiliza otros referentes para su reflexión, en los cuales no hay espacio para nociones de orden trascendental.

En lo relacionado con la justicia cabe acotar que la propuesta de Leibniz, a pesar de su estructura metafísica, propone la aplicación de una virtud

16 Leibniz, "Del libre albedrío", 113. 
que se comprende de manera paulatina, pero que luego de su implementación se convierte en una de las principales características de quien ostenta el poder. Leibniz establece los vínculos de la justicia con el poder ejercido por el Estado, de forma que se trasforma en el criterio para orientar múltiples acciones relacionadas con el derecho y su aplicación en la sociedad.

La libertad, más allá de su referente con la trascendencia, abre espacio a motivaciones racionales para orientar las acciones; estas inclinaciones no se limitan al ámbito metafísico, ej: obedecer a Dios para ser libres, sino que son fruto de la especulación y aplicación del pensamiento a circunstancias concretas.

Puede afirmarse, entonces, que para Leibniz no es válido proponer una libertad que carezca de motivaciones racionales que orienten su actuar, toda manifestación de la libertad se caracteriza por sustentarse en dichas determinaciones.

\section{Referencias}

Carvajal, Álvaro. "Ética y Política en Leibniz". Revista de Filosofía de la Universidad de Costa Rica, 37, 92 (1999).

De Salas, Jaime. "Prólogo". En Escritos políticos. (Madrid: Centro de Estudios Constitucionales) (1979).

Di Castro, Elizabetta. "El concepto de justicia en Leibniz". Revista de Filosofía de la Universidad de Costa Rica, 51, 129-131 (2012).

Leibniz, Gottfried Wilhelm. "Retrato de un príncipe". En Escritos políticos, editado por Jaime De Salas. Madrid: Centro de Estudios Constitucionales, 1979.

Leibniz, Gottfried Wilhelm. "Meditación sobre la noción común de justicia”. En Escritos políticos, editado por Jaime de Salas. Madrid: Centro de Estudios Constitucionales, 1979.

Leibniz, Gottfried Wilhelm. Elementos del derecho natural. Madrid: Tecnos, 1991.

Leibniz, Gottfried Wilhelm ."Acerca de la libertad carente de elección”, en Escritos en torno a la libertad, el azar y el destino, editado por Concha Roldán. Madrid: Tecnos, 1990.

Leibniz, Gottfried Wilhelm, "Del libre albedrio", en Escritos en torno a la libertad, el azar y el destino, editado por Concha Roldán. Madrid: Tecnos, 1990.

Leibniz, Gottfried Wilhelm. "Sobre la libertad de indiferencia", en Escritos en torno a la libertad, el azar y el destino, editado por Concha Roldán. Madrid: Tecnos, 1990.

Leibniz, Gottfried Wilhelm ."Definición de libertad”, en Escritos en torno a la libertad, el azar y el destino, editado por Concha Roldán. Madrid: Tecnos, 1990.

Roldán, Concha. "Prólogo", en Escritos en torno a la libertad, el azar y el destino, editado por Concha Roldán. Madrid: Tecnos, 1990. 